\title{
Neuroeducação e dificuldades de leitura e escrita: análise à luz da Neurolinguística Discursiva
}

DOI: http://dx.doi.org/10.21165/el.v50i3.2904

\author{
Isabella de Cássia Netto Moutinho' \\ Maria Irma Hadler Coudry ${ }^{2}$
}

\section{Resumo}

Um dos objetos de análise da Neurolinguística Discursiva (ND) é o aumento de cursos que relacionam os estudos da cognição, a psicologia e a neurologia - as chamadas neurociências - com a educação. O objetivo desses cursos, em geral, é ajudar o professor a compreender processos biológicos envolvidos na aprendizagem e o funcionamento cerebral, o que, em tese, ajudaria a compreender as dificuldades dos alunos e repensar as práticas pedagógicas. Neste trabalho, analisamos o recente avanço das chamadas Neurociências ou a Neuroeducação sobre os cursos de formação de professores e sua abordagem das dificuldades de aprendizagem, sobretudo da Dislexia. À luz da ND, analisamos um artigo representativo do ponto de vista que a Neurociência divulga sobre a Dislexia e propomos um contradiscurso para esta perspectiva.

Palavras-chave: neuroeducação; dislexia; dificuldades escolares.

1 Universidade Estadual de Campinas (UNICAMP), Campinas, São Paulo, Brasil; isabella.bel@gmail.com; https://orcid.org/0000-0001-7890-9941

2 Universidade Estadual de Campinas (UNICAMP), Campinas, São Paulo, Brasil; mihadler@gmail.com; https://orcid.org/0000-0003-2724-1608 


\title{
Neuroeducation and reading and writing difficulties: the neurolinguistics analysis
}

\begin{abstract}
One of Discursive Neurolinguistics' (DN) objects of analysis is the increase in courses that link cognition, psychology, and neurology - the so-called neurosciences - to education. The goal of these courses, in general, is to help the teachers to understand biological processes involved in learning and brain functioning, which, in theory, would help to understand students' difficulties and rethink pedagogical practices. In this paper, we analyze the recent advances by the so-called Neurosciences or neuroeducation on teacher training courses and its approach to learning difficulties, especially Dyslexia. Based on DN, we analyzed a representative article that shows the point of view that Neuroscience discloses about Dyslexia, and we propose a counter-discourse for this perspective.
\end{abstract}

Keywords: neuroeducation; dyslexia; school difficulties.

\section{Introdução}

Verifica-se, tanto no mercado editorial quanto na oferta de cursos voltados aos profissionais envolvidos com a educação (professores, psicopedagogos, fonoaudiólogos, psicólogos), uma tendência temática nos últimos anos: a busca da compreensão das dificuldades escolares nas chamadas neurociências ${ }^{3}$. Além das publicações e cursos, é possível constatar também o surgimento de novos campos de atuação e novas habilitações profissionais relacionadas às neurociências, como a Neuroeducação, a Neuropsicopedagogia, a Neuropsicologia e a Neurofonoaudiologia. Com mais frequência, são oferecidos workshops e cursos livres de curta duração por especialistas das mais diversas áreas sobre a relação entre a neurologia e a aprendizagem. Neste contexto, o mercado editorial se aproveita dessa tendência e cada vez mais publica livros sobre o que se chama de neurociência aplicada à prática pedagógica: uma rápida busca em um portal de pesquisa na internet com as palavras "livros, Neuroeducação" mostra indícios do aumento de publicações sobre o tema. Nas redes sociais, pode-se observar que o tema se faz presente em clínicas para as quais encaminham as crianças com dificuldades, uma vez que há a divulgação de cursos, linhas teóricas, oferecimento de acompanhamentos

3 Como indício desse fenômeno, podemos mencionar o volume de publicações identificadas pelo Google Acadêmico nas quais os termos "neuropsicopedagogia", "neurofonoaudiologia" e "neuroeducação" foram encontrados. Por exemplo, o portal identificou a expressão neuropsicopedagogia em apenas 13 publicações anteriores ao ano 2000; entre 2001 e 2010, o termo foi localizado em 53 publicações; já com o recorte entre os anos de 2011 a 2018, a busca retorna 733 resultados. Com o termo neuroeducação identifica-se ascensão similar: uma única publicação antes do ano 2000; 25 resultados entre 2001 e 2010; e 483 resultados entre 2011 e 2018. 
clínicos para crianças e orientações a pais e professores partindo da perspectiva das neurociências.

Identificada essa tendência e, sobretudo, o fato de que essa nova linha teórica aborda as dificuldades de aprendizagem de leitura e escrita, a ND propõe uma análise desta nova área que se integra à educação. Neste trabalho, analisamos um capítulo de livro representativo da perspectiva da neurociência sobre a Dislexia. 0 artigo foi escolhido porque a ND se consolidou como área da linguística que estuda a relação entre cérebro, sujeito e linguagem para compreender o processo de aprendizagem da leitura e da escrita 4 .

\section{Fundamentação teórica}

As dificuldades escolares relacionadas à leitura e à escrita têm sido um dos focos de estudo da Neurolinguística de orientação Discursiva (abreviada como ND) desde $1982^{5}$. Ao longo desses anos de estudo, a área, fundada no Instituto de Estudos da Linguagem da UNICAMP pela professora Maria Irma Hadler Coudry, identificou o excesso de laudos com diagnósticos de patologias relacionadas ao aprendizado de leitura e escrita, como a Dislexia, o TDAH, o Transtorno Específico da Aprendizagem, o Déficit do Processamento Auditivo, dentre outras. Um exemplo disso é a estimativa de ocorrência dos Transtornos de Aprendizagem apontadas pelo Manual Diagnóstico e Estatístico de Transtornos Mentais: haveria uma variação de $2 \%$ a 10\% das crianças em idade escolar. Esses índices são amplamente criticados mesmo no âmbito da medicina, de modo que alguns médicos (MOYSÉS, 2001) problematizam inclusive que se trate desses índices com porcentagem, o que só ocorre quando o objeto de análise é uma epidemia e não supostos transtornos neurofuncionais. Com o objetivo de não apenas investigar melhor o processo que culmina na patologização das dificuldades normais relacionadas à leitura e à escrita, mas de também intervir no processo de aprendizagem de crianças rotuladas e estigmatizadas pela patologia, a professora Maria Irma Hadler Coudry criou, em 2004, o Centro de Convivência de Linguagens (CCazinho).

\footnotetext{
4 Os trabalhos desenvolvidos no interior da ND sobre o excesso de patologias relacionadas à leitura e à escrita partem de dados coletados no Centro de Convivência de Linguagens, o CCazinho. O centro promove a convivência de crianças com dificuldades de leitura e escrita em práticas discursivas verbais e não verbais que sejam significativas para elas e que envolvam a leitura e a escrita. O objetivo do CCazinho é investir na entrada das crianças para o mundo das letras, isto é, em seu processo de alfabetização, a despeito da suposta patologia que apresentam.

5 No segundo semestre de 1982, foi oferecida, pela Profa Coudry, pela primeira vez, a disciplina Neurolinguística para o Bacharelado de Linguística, marcando o início da constituição da área na Graduação. Em agosto de 1986, com a defesa de seu doutoramento, foi oferecida, pela citada professora, a disciplina Neurolinguística I, na pós-graduação, marcando o início da área na Pósgraduação.
} 
Neste centro, pesquisadores de diversas áreas (Letras, Linguística, Pedagogia, Fonoaudiologia, Física, Geologia, etc.) acompanham longitudinalmente crianças que chegam, na grande maioria das vezes, com algum diagnóstico. Ocorre que ao longo do acompanhamento voltado a compreender e ajudar a criança a superar suas dificuldades, com base em teorias da linguagem e do cérebro, a patologia não se confirma: todas as crianças que passaram pelo CCazinho se alfabetizaram. As questões que se revelaram como barreiras para o aprendizado tinham outras origens e muitas vezes estavam encobertas pelo laudo que, por sua vez, justificava problemas de ordem afetiva, social, cultural, política e pedagógica.

Esse processo de mascarar problemas de outras esferas com o rótulo da patologia é chamado, no interior da ND, de patologização de dificuldades normais do aprendizado e de medicalização, segundo diversos outros autores que se debruçam sobre a questão, como Moysés e Collares (2010), Conrad (1992) e Signor e Santana (2016). O processo não se limita apenas à profissão médica, mas a todos os profissionais da área clínica que se relacionam com a criança que enfrenta dificuldades na escola, como psicopedagogos e fonoaudiólogos, que partem da racionalidade médica para compreender questões escolares. Neste contexto, diversos pesquisadores da ND problematizam os dispositivos históricos e os da contemporaneidade que disparam esse processo de patologização e, ao desvendá-los, se dedicam, através das pesquisas (de iniciação científica, mestrado, doutorado e pós-doutorado), a construir um contradiscurso que responda a este processo de maneira a denunciá-lo e não permitir que tantas crianças sejam marcadas por uma patologia que não têm (COUDRY, 2007, 2009; BORDIN, 2010; MÜLLER, 2018; RIGHIGOMES, 2014; MOUTINHO, 2019).

Partindo de uma metodologia heurística de análise de dados, a ND evidencia as hipóteses (ABAURRE, 2006) que a criança constrói nas diversas fases do aprendizado da escrita e entende que a pré-história da escrita (LURIA, 2001), as práticas de letramentos escolares e cotidianos nas quais está inserida são determinantes desse aprendizado. Rejeitamos as perspectivas que entendem que a capacidade de aprendizagem é resultado apenas da presença de aptidões biológicas - que justificam as dificuldades escolares com uma patologia (COUDRY, 2007, 2009). Para a ND, tais perspectivas não tomam a alfabetização como atividade social e cultural complexa, não consideram sua relação com a fala, ignoram os fatores sociais, culturais, pedagógicos, políticos e econômicos que determinam a entrada das crianças no mundo das letras. Três conceitos da ND são fundamentais para a compreensão do processo singular do aprendizado de leitura e escrita: cérebro, sujeito e linguagem.

Para a ND, a compreensão do cérebro parte de sua historicidade, plasticidade e funcionamento complexo e integrado, conforme os estudos de Vygotsky (2001), Luria (1979) e Freud (1973). Para Vygotsky (2001), é preciso compreender a noção de variação funcional: ainda que o cérebro seja um patrimônio biológico comum a todos, é inegável 
a variação de funcionamento e de modos de organização neurológica. Para os autores, essa variação é determinada pelas diferentes relações históricas, sociais e culturais que atravessam e determinam os sujeitos, mediadas pela linguagem. A linguagem não pode ser, portanto, reduzida à comunicação, codificação e decodificação, mas sim construção coletiva, histórica e social, o que confere a ela um caráter de indeterminação semântica e sintática e exige o contexto para ser interpretada (FRANCHI, 1992). O sentido não está dado a priori: é construído no interior do contexto discursivo e nas práticas de linguagem, devendo ser levados em conta obrigatoriamente a história das expressões e o caráter singular da intersubjetividade estabelecida na interlocução. A linguagem é uma atividade constitutiva: tanto de sujeitos, quanto de si mesma (FRANCHI, 1992). Na mesma direção, a concepção de sujeito que se alinha às concepções de cérebro e linguagem apresentadas se distancia radicalmente da concepção de sujeito padrão e mediano, proposta pela literatura médica. O sujeito é constituído na e pela linguagem (FRANCHI, 1992) em um processo singular de determinação sócio-histórica e, uma vez singular, o sujeito da ND é indeterminado e escapa de idealizações. A linguagem assume, portanto, a função de regulação dos processos psíquicos e de especialização das funções psicológicas superiores, além da linguagem, como a atenção, a memória, corpo (práxis), raciocínio intelectual, percepção, imaginação, vontade. Em suma, para a ND, o desenvolvimento dessas funções não é de origem biológica e sim social, sendo esta uma das premissas centrais que afastam a ND da literatura médica que trata dos chamados "transtornos da aprendizagem", em especial os que envolvem o aprendizado da leitura e da escrita. Os trabalhos desenvolvidos na área evidenciam o excesso de diagnósticos de patologias relacionadas ao aprendizado, sobretudo a Dislexia e o Transtorno do Déficit de Atenção com ou sem Hiperatividade. Não negamos que existam patologias que podem comprometer a aprendizagem (COUDRY, 2010), mas, ao mesmo tempo, problematiza o que a clínica considera como sintoma de Dislexia, mostrando com análises de dados de escrita e leitura que tais dificuldades são normais e esperadas no processo de aprendizagem. Desse modo, alertamos para o número crescente de crianças diagnosticadas com Dislexia que de fato não têm a patologia. E por que isso? É preciso analisar essa situação considerando o mundo das compras em que vivemos, apelados por um consumo despercebido, em que os pais querem o melhor para seus filhos e acabam seduzidos pelas tendências de avaliação e intervenção clínica que se anunciam no mercado como novidade no campo pedagógico, blindadas de críticas pelo caráter científico que assumem e como a única solução para as dificuldades de aprendizageḿ.

\section{Análise de dados}

A tendência de se adotar uma perspectiva cognitivista para a compreensão do processo de alfabetização e para as dificuldades - patológicas ou não nele envolvidas - está presente não somente nos cursos de formação de professores e nos livros sobre o tema,

6 A análise que segue contém dados e reflexões apresentadas na tese de doutorado de uma das autoras. 
mas também nas políticas públicas. Em 2019, o presidente Jair Bolsonaro emitiu um decreto que estabelece as diretrizes da nova Política Nacional de Alfabetização, na qual o governo normatiza a fundamentação de programas e ações em evidências provenientes das ciências cognitivas, bem como a instrução fônica, amplamente defendida entre os autores que se localizam no referencial teórico das neurociências. Desse modo, esse fenômeno merece atenção e análise da Neurolinguística Discursiva, não somente por envolver um dos objetos de estudo da área, mas por se revelar uma tendência para os cursos de formação de professores e outros profissionais da educação pelo suposto respaldo científico. Assim, escolhemos o capítulo de um livro que é representativo dessa perspectiva para análise, apresentada neste item.

O portal de vendas Amazon permite fazer uma busca pelos livros mais vendidos por tema ${ }^{7}$. Dentre os cinco livros mais vendidos sobre o tema Neuroeducação, dois abordam os chamados transtornos da aprendizagem, o que é um indício de que esta nova tendência que relaciona Neurociências e Educação tem forte ligação com a literatura médica. Escolhemos analisar neste artigo um capítulo sobre o diagnóstico de Dislexia que faz parte do livro mais vendido da área Neuroeducação - Neurologia e aprendizagem - abordagem multidisciplinar. O título do capítulo é Dislexia: varlendo contra o vento, de Asta Altreider. A autora é fonoaudióloga, psicopedagoga, especialista em Alfabetização pela Federação de Estabelecimento de Ensino Superior de Novo Hamburgo (Feevale) e consultora em transtornos da aprendizagem em escolas da região metropolitana de Porto Alegre. A autora inicia o capítulo com algumas problematizações sobre a precarização da escola na contemporaneidade e a inadequação das práticas pedagógicas. Entretanto, na contramão da análise da ND, para a autora, não é a desorganização escolar e a inadequação das práticas que geram o fracasso escolar, mas sim as dificuldades das crianças para aprender a ler e a escrever: o déficit está na criança. Para a autora, estes fatores são os impeditivos para que os professores possam identificar alunos disléxicos e dispensar práticas adequadas àqueles já diagnosticados. Para ela, a escola é onde se manifestam dificuldades resultantes da Dislexia e não das desigualdades sociais:

A escola é o espaço por excelência onde se manifestam as dificuldades resultantes da dislexia: a lentidão ou inabilidade para ler como os outros, a

7 No tema Neuroeducação, no primeiro trimestre de 2019, os cinco livros mais vendidos eram, respectivamente, do primeiro para o último: Neurologia e aprendizagem - abordagem multidisciplinar (organizado por Rotta, Bridi Filho e Bridi), Neuroeducação - a relação entre saúde e educação (organizado por Heber Maia), Neurociência e transtornos de aprendizagem, (livro esgotado, escrito por Marta Pires Relvas), Neurociência, Neuroeducação e Neuropsicopedagogia (escrito por Salete Anderle e Roberto Rodrigues) e Neurociência e aprendizagem: processos básicos e transtornos (escrito por Bruna Brandão Velásquez e Pedro Ribeiro). Este rastreamento de livros e categorias no site da Amazon ocorreu em 2019. Atualmente, a categoria Neuroeducação não existe mais no portal da Amazon, mas sim como uma tag de busca. Os livros dessa categoria, entretanto, estão inseridos na categoria Educação. 
exposição diante de pares evidenciando a incompetência, a rotina diária de ter de fazer o que não sabe fazer, o raro preparo do professor em saber lidar com essa situação... e o vento começa a soprar contra! Com longa experiência de contato com escolas e interferindo no manejo de pacientes com dislexia, a multiplicidade de atitudes encontradas não poderia ser maior: a) há escolas (raras) com esquema previamente organizado: tarefas são readequadas, usam-se tecnologias assistivas e provas são feitas em um espaço específico acompanhadas de um responsável "leitor"; b) há escolas que, mesmo recebendo um diagnóstico formal, preferem ignorá-lo e mantêm as tarefas, provas e avaliação exatamente iguais às dos colegas, pois perdura o mito de que proporcionar modos diferentes de ensinar significa privilegiar injustamente algum aluno; c) há escolas, diga-se, professores, que desconhecem a dislexia... nesse caso, preferem dizer "carinhosamente" que cada um tem seu ritmo ou chamá-lo ostensivamente de preguiçoso". (ALTREIDER, 2015, p. 230).

Primeiramente, nos estranha o mito citado pela autora: geralmente, os professores afirmam que oferecer atendimento individualizado e planejar atividades que contemplem as dificuldades de cada aluno é inviável pela falta de tempo, pela quantidade alta de alunos em sala, ou pela exigência institucional de que se cumpra o material didático escolhido pela escola. Além disso, consideramos graves as últimas afirmações da autora: para ela, as dificuldades ou a lentidão no aprendizado não são evidências de que os alunos aprendem em ritmos diferentes, mas sim evidência de dislexia. Com isso, a autora acusa o professor de se beneficiar de teorias amplamente divulgadas na Educação sobre o ritmo da aprendizagem (VYGOTSKY, 2001) para justificar as dificuldades dos alunos e, por isso, ignorarem o que seria, de fato, o problema: a dislexia não diagnosticada. A autora segue, aparentemente, se dirigindo àqueles que questionam o diagnóstico de Dislexia e a existência da patologia tal qual é definida e retoma a prevalência da Dislexia por país:

O transtorno de aprendizagem - dislexia - ocorre em todos os lugares do planeta, com diferentes índices de incidência. No Japão, a taxa é de 1\%; nos Estados Unidos, entre 5\% e 6\%; na Itália estudo recente aponta para 3\%; e no Brasil, a estimativa é de $5 \%$. Na nossa região (metropolitana de Porto Alegre e Vale do Rio dos Sinos), há escolas com mais de 500 alunos que não identificam em seu quadro nenhum aluno disléxico. Isso está longe de ser indício de ausência do quadro e está mais perto de ignorar sua existência. (ALTREIDER, 2015, p. 230).

Mesmo com os problemas de organização textual do último período, é possível entender que, para a autora, o fato de que existam escolas com mais de 500 crianças sem diagnóstico de Dislexia não significa que a doença não exista, mas sim que não foi diagnosticada ainda. Ou seja, em um montante de 500 crianças, é impossível que nenhuma seja disléxica. A autora tece considerações sobre o que ela considera normal e o patológico no aprendizado da escrita e como a dislexia se manifestaria em cada 
etapa do percurso escolar. Na perspectiva da autora, já no $1^{\circ}$ ano é possível identificar sinais de dislexia pelo ritmo de aprendizagem dos alunos. Se mais lento, se diferencia dos demais da turma e merece atenção. Os alunos não disléxicos "armazenam palavras, fazem associações, descobrem semelhanças e diferenças entre as palavras e têm prazer com essas atividades" (ALTREIDER, 2015, p. 231). Já o aluno com sinais de Dislexia não reconheceria as vogais com facilidade, teria interesse restrito na produção gráfica e não gosta de mostrar o que aprendeu porque possivelmente não aprendeu. No $2^{\circ}$ ano, para a autora, as diferenças são mais evidentes:

No segundo ano, as diferenças se polarizam: alunos que não aprenderam a ler durante $01^{\circ}$ ano, porém não disléxicos, começam a processar os mecanismos de leitura e escrita. A leitura começa a fluir um tanto silabada, mas com uma característica bem objetiva: querem saber o que está escrito. Releem, prestam atenção na sonoridade fonológica e, em seguida, refazem a palavra enunciando-a com compreensão. O aluno que mantém a dificuldade de reconhecimento imediato das letras, e quando está em situação de leitura oral, substitui ou omite partes da palavra de tal modo que fique sem significado. Esse aluno continua sua batalha de decodificação dos grafemas e não consegue dar-se conta de que não está entendendo o que está escrito. "Juntar" as letras e entender o que elas significam é uma tarefa hercúlea e, claro, ele não consegue fazê-lo. (ALTREIDER, 2015, p. 231).

A autora mostra pré-julgamentos e preconceitos com a criança que tem dificuldades. O prazer e o interesse pela leitura e pela escrita são, surpreendentemente, indícios de dislexia e critério diagnóstico, o que é, portanto, ponto que merece ser observado pelo professor que eventualmente lê este livro. Não há considerações sobre os fatores sociais que determinam o interesse pela leitura: a pré-história da escrita (LURIA, 2001), os desenhos desencadeados pelas narrativas ou vice-versa, as práticas de letramento na escola e fora dela não fazem parte da reflexão. Apenas questões orgânicas que provocariam a dislexia seriam determinantes do interesse e do prazer em aprender. A prática pedagógica não é considerada, apesar de ser fator determinante das atitudes da criança na escola quando motivadora, interessante e significativa. Ademais, a autora desconhece o que está envolvido na leitura em voz alta ao afirmar que o disléxico não entende o que lê e isso é sintoma de patologia. A ND mostra, com dados que envolvem o aprendizado da leitura (MOUTINHO, 2019), que, ao ler em voz alta, a criança que tem dificuldades concentra sua atenção e esforço no ritmo, na entonação, na tentativa de fazer uma leitura precisa. A compreensão fica em segundo plano, já que a criança ou mesmo o adulto se preocupa em possibilitar que o ouvinte compreenda o texto lido. Por isso, a ND não utiliza a leitura em voz alta antes que a criança saiba ler com uma certa fluência de modo que compreenda o que lê, ou seja, quando não há mais episódios de silabação na leitura, que se torna morosa e que dificulta compreender o que se lê. O que é inaceitável para um estudioso da linguagem é a leitura silabada e lenta aparecer como sintoma de patologia e não como parte do processo de aprendizagem. Já no terceiro 
ano, "o grupo lê com fluência pequenos textos e começa o desafio da ortografização da escrita. $\mathrm{O}$ aluno potencialmente disléxico ainda se embaralha com a diferença do /O/ e do /A/ e com o mistério do /p,q,d,b/" (ALTREIDER, 2015, p. 231).

Por fim, a autora afırma que, no quarto ano, as crianças adotam estratégias de compensação, como colar dos colegas, se atentar mais à expressão fisionômica do professor e o "balbuciar em voz baixa enquanto escreve" (ALTREIDER, 2015, p. 231). A experiência dos pesquisadores da ND com crianças em processo de alfabetização mostra que as crianças se apoiam na fala para escrever desde o início, não podendo este fato ser uma estratégia de compensação usada apenas no quarto ano, quando a criança já tem 10 anos. Ademais, apontamos a inadequação do emprego do termo balbuciar para escrever. O balbucio é sonorização feita pelos bebês e é analisado por HellerRoazen (2010) como uma das questões-chave para o desenvolvimento da fala e para a consolidação das impressões proprioceptivas (LURIA, 1991). Conforme aponta Cagliari (1989), a criança sussurra para escrever, o que, inclusive, faz com que em muitos casos a criança ensurdeça muitas consoantes (e acabe escrevendo pola por bola, cato por gato, etc.), o que gera o que se chama de trocas de letras ${ }^{8}$. Segundo Altreider, o diagnóstico deve ser feito somente no $3^{\circ}$ ano do Ensino Fundamental, já que muitas dificuldades acabam sendo solucionadas no percurso escolar e no $3^{\circ}$ ano é possível identificar melhor as crianças que persistem com problemas. A persistência das dificuldades é, portanto, o fator chave para o diagnóstico.

A autora não tece nenhuma problematização sobre a prática pedagógica ou outras questões afetivas, sociais e culturais, e como elas podem contribuir para que as dificuldades persistam. Sobre a consolidação do diagnóstico, a autora afırma a necessidade de uma equipe multidisciplinar, e ressalta o papel dos professores através dos relatórios escolares e dos pais, que fornecerão as informações sobre prováveis questões genéticas que permitirão facilitar a identificação de algum transtorno da criança, bem como informações sobre a observação da criança no contexto domiciliar. Na perspectiva da autora, a família é elemento de investigação pela herança genética e pelo que pode dizer dos filhos. A vida dos pais, a relação deles com a escolarização, com a leitura e com a escrita não são consideradas como um modelo que a criança reproduz, como ressalta a ND. Apresentamos, a seguir, um trecho do capítulo que diz muito sobre a concepção de linguagem que embasa a perspectiva da autora.

8 A ND problematiza o termo "troca de letras" como sintoma de dislexia ou de outro transtorno que afetaria a leitura e a escrita: o termo troca remete a um processo irrefletido, no qual a criança escolheria aleatoriamente qualquer letra para escrever. A análise dos dados da ND mostra que as chamadas trocas são hipóteses de representação gráfica construídas ora com fundamentação na fala da criança, ora com fundamentação nos conhecimentos que ela tem sobre a ortografia. Abaurre (2001) critica essa nomenclatura sobretudo porque no processo de alfabetização podem ser identificados fones surdos com traços de sonoridade e vice-versa, instabilidade levada a cabo pela presença da fala na escrita, conforme argumentam Coudry e Freire (2017). 
O entendimento das vogais passa a assumir grande importância nesse processo de observação de indícios dislexiformes. "O" e "A" costumam trazer muitos conflitos de memória fonológica; " $\mathrm{O}$ " e " $\mathrm{U}$ " apresentam-se como "inimigos mortais". A criança não consegue realmente perceber a diferença. O que para os não disléxicos é simples e óbvio para o disléxico é complexo e sem sentido. Ademais, convenhamos: nossa linguagem oral piora significativamente essa discriminação. O mesmo acontece com o "E" e o "I". Sons homófonos, como $\mathrm{D} / \mathrm{T}, \mathrm{P} / \mathrm{B}, \mathrm{G} / \mathrm{J}$ trazem consigo necessidades de ampliar habilidades de memória fonológica, discriminação visual e discriminação auditiva. Não bastasse a língua oral repleta de vícios, a aprendizagem da comunicação gráfica costuma passar por letra de imprensa maiúscula (letra bastão), letra script e cursiva. Quando o disléxico é apresentado à letra script, entra em colapso: as dificuldades na percepção e orientação espacial impedem o entendimento da diferença entre: " $p$ ", "q", "d", "b". (ALTREIDER, 2015, p. 237).

Analisando este trecho, assumimos que a autora esteja tratando de hipóteses como sapu por sapo e peixi por peixe, comum na escrita inicial e representativas do alteamento dessas vogais em final de palavra na maioria das variedades do português brasileiro. Não é possível compreender, porém, de quais conflitos a autora trata quando menciona trocas entre "O" e " $A$ ". Ressaltamos, ainda, que as diferenças entre essas vogais em final de palavra não são simples e óbvias: todas as crianças, não apenas os que demonstram mais dificuldades, em algum momento do processo de alfabetização não escapam a esta hipótese porque se apoiam na fala para escrever. A intervenção do professor é crucial, de forma que explicite as diferenças entre a escrita e a oralidade e chame a atenção para o fato de que não escrevemos como falamos, e que leva tempo, exposição à língua escrita, escrita e reescrita para que essas diferenças sejam automatizadas. Para a ND, essas ocorrências não evidenciam um problema de memória fonológica associado à Dislexia, mas um fenômeno comum a todas as crianças em fase de alfabetização, e cuja persistência pode depender das práticas pedagógicas, da qualidade da relação que a criança tem na escola e fora dela com a língua escrita e do valor social que ela atribui à aprendizagem.

Queremos chamar a atenção para o erro conceitual e o desconhecimento de questões básicas de linguística que a autora demonstra ao dizer que $D / T$ e $P / B$ são "sons homófonos", além do erro de representação fonética. Tanto [d] quanto [t] são oclusivas alveolares que se distinguem justamente pelo traço de sonoridade, enquanto [p] e [b] são oclusivas bilabiais que se distinguem pelo mesmo fator. Consideramos grave também a afırmação de que a criança não percebe a diferença entre esses pares pelas dificuldades de percepção e orientação espacial associadas à Dislexia, já que o que as diferencia é justamente o traço de sonoridade, que nada tem a ver com orientação espacial. Vemos que o conceito de linguagem, para a autora, se restringe à comunicação gráfica, e que questões primordiais para entender a alfabetização, como as variedades linguísticas, são, nesta perspectiva, vícios de linguagem. Pode-se ainda destacar termos usados pela autora 
de maneira inadequada e irresponsável, como dizer que as vogais são inimigas mortais dos disléxicos, e que as crianças entram em colapso diante de algumas consoantes.

Por fim9, a autora apresenta um estudo de caso que interessa muito à ND, pois há a anamnese, o histórico escolar e dados de escrita da criança. A criança avaliada é uma menina de 8 anos e nove meses cuja família buscou avaliação neurológica por orientação escolar. A professora define a menina como alguém que tem "dificuldades de concentração, impulsividade, não segue instruções, entra em conflito com colegas e não reconhece o alfabeto" (ALTREIDER, 2015, p. 235). Não houve alterações nos resultados da tomografia computadorizada. Assim, o médico receitou apenas ansiolítico.

$\mathrm{Na}$ anamnese, a mãe relata que a gravidez e o parto foram normais. Ana Maria pesou 2,450 kg e mediu $47 \mathrm{~cm}$. Nasceu com um rim maior e logo foi medicada. Mamou até os 3 meses e passou para mamadeira porque a mãe "não tinha paciência". Somente aos 5 anos passou a ter peso normal. Andou com 9 meses, falou cedo e "perfeitamente", largou fraldas (controle esfincteriano) aos 2 anos, aprendeu logo a andar de bicicleta e skate, prefere brincar na casa de árvore a ver televisão. Teve sono agitado até a entrada recente da medicação. Dorme com a irmã mais velha (em cama de casal) e frequentemente pede para dormir com os pais, no que não é atendida. (ALTREIDER, 2015, p. 236).

Nos relatos escolares, não há registros de problemas de adaptação até o último ano da Educação infantil, quando Ana Maria teve problemas de relacionamento com a professora. A professora queria que ela se sentasse para fazer as atividades, mas ela

\begin{abstract}
9 A autora cita um estudo italiano sobre a Dislexia chamado "O iceberg submerso da Dislexia", feito pela Comissão Nacional sobre Epidemiologia de Dislexia. Cabe aqui ressaltar o uso do termo epidemia de Dislexia, duramente criticado por Moysés (2001) quando utilizado para tratar de problemas que incidem sobre a aprendizagem por que são, na perspectiva clínica da autora, decorrentes de questões sociais, culturais e pedagógicas. O uso do termo localiza cada vez mais a questão da aprendizagem na esfera clínica e afasta a problematização feita pelas ciências humanas. Segundo o estudo, a hipótese inicial de que há mais crianças com Dislexia do que as já diagnosticadas na Itália foi corroborada. A aplicação de testes padronizados de leitura e escrita em escolas italianas apontou que a prevalência de Dislexia na Itália é de 3,1\% e que duas dentre três crianças disléxicas entre 8 e 9 anos não tinham o transtorno identificado. A autora cita essa pesquisa para ilustrar sua hipótese sobre o Brasil: "a ciência mostra que a base neural é a mesma em diferentes línguas e mesmo assim ocorrem diferentes prevalências na comparação cruzada dessa pesquisa com o resultado de pesquisas feitas com crianças de língua inglesa" (ALTREIDER, 2015, p. 234). Mais uma vez, a autora não problematizas as diferenças significativas entre os sistemas de ensino de países diferentes, nem as condições sociais e afetivas que determinam a aprendizagem. A constatação de que há duas entre três crianças disléxicas não identificadas reforça o quanto a dislexia é subestimada no universo escolar, na opinião da autora, e não um problema de excesso de diagnósticos e equívocos na avaliação, segundo a ND.
\end{abstract}


preferia continuar brincando. De acordo com a mãe, a professora pegou implicância com ela, o que fez com que, no ano seguinte, ela regredisse e deixasse de gostar de ir à escola.

Ana Maria era dispersa, não mostrava interesse nenhum nas letras e números e tinha uma atitude de quem não se importava com a insistência da professora. Temas passaram a ser um problema. Nunca queria fazê-los, e a família montava uma logística de revezamentos para ajudá-la. No $2^{\circ}$ ano, regrediu mais ainda. Referia não querer ir para a escola. No $3^{\circ}$ ano, atualmente, ainda não sabe ler e não mostra interesse em escrever. Só brigando com ela. A professora atual pensa que a família protege demais a menina, que fazem tudo que ela quer, que é "mimada" demais e recomenda retirar as bonecas dela. Costuma chegar em casa e contar que chorou na escola porque a professora gritou com ela. [...] Ela é, "esperta e carismática, afetuosa, mas impulsiva, tem dificuldades de seguir instruções, não consegue concentrar-se por muito tempo, fala quando não é sua vez, exige que prestem muita atenção nela, reconhece o alfabeto, porém não atribui ainda valor sonoro a todos os signos do sistema alfabético, nas palavras da orientadora. (ALTREIDER, 2015, p. 236).

Para a escola, independente do diagnóstico de Dislexia consolidado, Ana Maria pode ser aprovada no final do ano letivo. Do ponto de vista da ND, essas informações permitem levantar hipóteses sobre os motivos pelos quais Ana Maria está barrada no aprendizado da escrita e não encontra motivação para aprender. Aparentemente, o processo de transição de Ana Maria da Educação Infantil para o Ensino Fundamental foi um pouco conflituoso e gerou sofrimento. Ela, que parece ser uma criança bastante ativa (prefere brincar na rua, na casinha da árvore do que ver TV), encontrou dificuldades para sentar e fazer lições. A Educação Infantil geralmente não exige esse tipo de atividades de controle do corpo e da atenção por tempo prolongado. Assim, a criança, ao chegar no Ensino Fundamental, se vê diante de outra dinâmica, em que ela não brinca mais o dia todo, não há o momento de dormir, ela circula menos pela sala de aula, passa menos tempo no parque de diversões e precisa se concentrar em novas aprendizagens.

Exige-se um sistema de atenção que nem sempre está pronto para essa nova rotina escolar e, se a escola não tiver um projeto de adaptação em que a criança aos poucos se habitue a essas novas exigências, conflitos como o que ocorreu entre Ana Maria e sua professora são comuns. A professora não entende os motivos pelos quais a criança se mostra resistente, instaura-se uma relação conflituosa, tensa, de impaciência e frustração tanto por parte da criança quanto por parte da professora e, em muitos casos, como esse, a professora e a equipe escolar começam a levantar a hipótese de uma patologia que justifique esse comportamento. A criança se cansa da escola, dos adultos que estão ali, das exigências que Ihe são feitas e não avança: mostra cada vez mais dificuldade em seu percurso escolar, já que as aprendizagens de certo período são base para novas aprendizagens (VYGOTSKY, 2001) e, uma vez não consolidadas, irão prejudicá-la com 
relação às expectativas escolares em torno dela. O fato de que ela não dorme também não é explorado pela autora, que não associa os efeitos da falta de sono ou de uma possível ansiedade como elementos que têm efeito na aprendizagem.

Há outros questionamentos que também não são feitos: que tipo de atividade era proposta à Ana Maria? Que sentido ela atribuía à aprendizagem da leitura e da escrita? Que valor social a escolarização tem em sua casa? Seus pais leem para ela, despertando seu interesse por livros? Quais atividades predominam em seu cotidiano? Qual é o lugar dos livros na dinâmica familiar? Nenhuma dessas considerações são feitas pela autora a respeito do aprendizado de Ana Maria. Sobre a família, constam no capítulo as considerações a seguir e o genetograma aqui reproduzido:

O genetograma apresenta particular importância no estudo do caso de Ana Maria, na medida em que é possível rastrear o traço genético de possíveis portadores do transtorno de dislexia não identificados. Todos os parentes listados do lado paterno de Ana Maria, desde o pai, apresentam dificuldades de aprendizagem. 0 pai é um construtor de renome, que tem ganhos financeiros que garantem uma vida confortável a todos, apesar de ter bastante dificuldade para a leitura. Prefere "ver" o noticiário do que ler jornal e, segundo a mãe de Ana Maria, se orgulha de "ganhar mais" do que muito diplomado. Dois irmãos abandonaram a escola precocemente por apresentarem significativas dificuldades de aprendizagem. Um dos filhos, aos 21 anos, ainda não conseguiu concluir o ensino médio. Esse perfil traça uma linhagem que permite levantar a hipótese de que haja uma estrutura genética "disléxica" na família paterna. (ALTREIDER, 2015, p. 237). 
Figura 1. Genetograma de Ana Maria

\section{Genetograma}

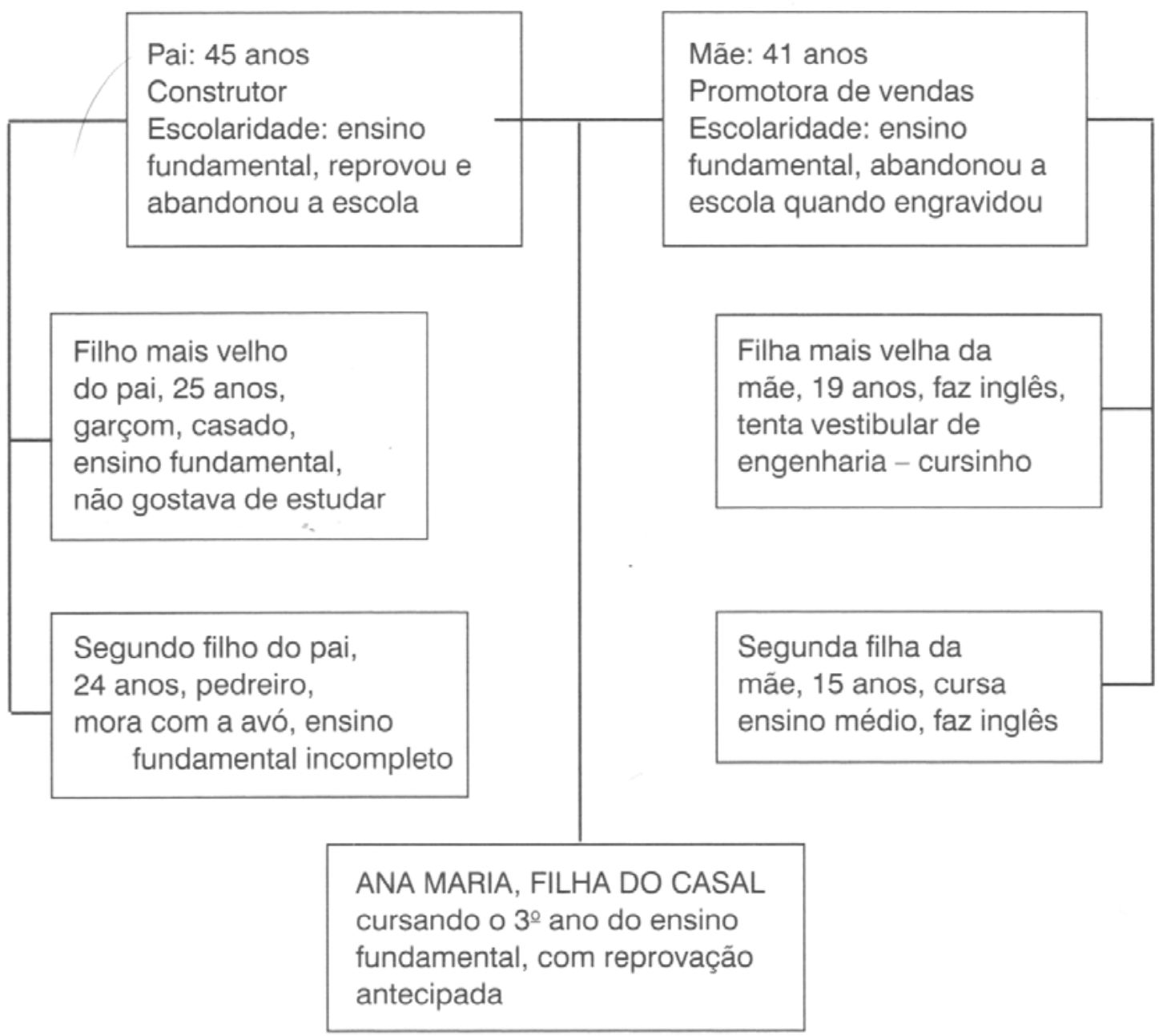

Fonte: Altreider (2015, p. 237)

A ND propõe um entendimento das informações do genetograma que difere da análise da clínica. O pai de Ana Maria trabalha como construtor sem instrução técnica. Historicamente, no Brasil, funcionários desta área trabalham desde a adolescência para ajudar a família porque estão inseridos em um contexto em que ganhar dinheiro para a sobrevivência imediata é mais importante do que estudar para ter uma posição social melhor e ganhar mais dinheiro a longo prazo, o que gera, consequentemente, pouco tempo para se dedicar aos estudos, dificuldades na escola e quase sempre a evasão escolar. A mãe de Ana Maria, por sua vez, abandonou a escola porque engravidou. Não há, aqui, nenhum tipo de menção ao fato de que tinha dificuldades escolares, mas não há também nenhuma problematização do fato de que as mulheres, quando engravidam 
na adolescência, sofrem pressões que fazem com que deixem a escola: no caso das famílias menos favorecidas, precisam parar de estudar para trabalhar e conseguir arcar com os custos da gravidez e da criança, bem como estar disponível para cuidar dela depois do nascimento. Vemos, também, que a família provavelmente lê pouco e assiste muita televisão, o que é compreensível em um contexto de dificuldades escolares, pouca valorização da escolarização (o pai se orgulha de ganhar muito sem ter diploma) e, consequentemente, poucas práticas de leitura e escrita no ambiente familiar. Para a ND, esse contexto tem efeito nas percepções de Ana Maria sobre a escola, sobre o sentido de aprender a ler e a escrever, sobre suas atividades preferidas e, associados ao ambiente hostil que as novas exigências fizeram da escola, o desinteresse de Ana Maria por ler e escrever é compreensível. Entretanto, na perspectiva da autora, esses fatos corroboram a hipótese de Dislexia: a situação de Ana Maria é resultante de herança genética e não dos contextos social, cultural, afetivo e pedagógico que ela integra. Diversos testes padronizados foram aplicados à Ana Maria, mas, para esta pesquisa, iremos focar nos testes de leitura e escrita.

Leitura: lê soletrando, porém, sem preocupação de entendimento de fluência integral da palavra: Ex, ODEIO = O DE E I O; ADORO A DE O RR O, na repetição proposta: DE E ERRE O; SAPO - ESSE A PÊ O. Na proposta de leitura da frase: O QUE MAIS GOSTO É DA MINHA FAMÍLIA, decodifica de forma semelhante ao exemplo acima = O QUE U E EME A MA I ESSE JO ESSE TÊ O É DA EME I MI ELE AGÁ, A EFE, A FA EME I MI ELE I A... no entanto, em alguns grafemas como M e $F$, faz uma tentativa de união silábica. Obviamente que a compreensão ficou totalmente comprometida. [...] Escrita: usa letra cursiva na produção gráfıca, que se resume a palavras soltas. Ao escrever SEXTA-FEIRA, escreve: SETATEIA (soletra rapidamente as mesmas sílabas até dar-se por satisfeita, termina e não relê nenhuma vez sua produção); MONSTRO = MOTO; TÊNIS = TIS; BONECA = BOECA. Escreve seu nome e o da sua cidade com fluência; solicitada a escrever DORMIR SOZINHA - referente ao fato de ter medo de dormir sozinha - escrever DUISINA. Escreve tudo muito rápido e não revê o que escreveu. (ALTREIDER, 2015, p. 238).

Ana Maria faz o que todas as crianças no início do processo de alfabetização fazem: ao ler, diz o nome da letra e depois junta formando sílabas. Comum a todas as crianças, esse processo necessita da mediação do adulto, que ajudará a criança a conhecer a sílaba e depois compreender a recursividade da escrita, ou seja, como ela pode escrever outras palavras a partir do seu nome, por exemplo. Ana Maria dá indícios de que está no início desse processo quando mostra que consegue ler algumas sílabas. Quanto à escrita, vemos que ela está às voltas com a sílaba complexa, como todas em fase inicial de alfabetização, além de apresentar uma escrita aparentemente infantilizada (evidenciada em SETATEIA e BOECA), que pode estar relacionada com o fato de que sua família também trata Ana Maria de maneira infantilizada, como denunciado pela professora que afirma que ela é mimada. Consideramos, ainda, os estudos de Amaral, Freitas, Chacon 
e Rodrigues sobre a representação da sílaba na escrita inicial. Para os autores, há uma oscilação na construção de hipóteses da representação da sílaba porque as crianças ora se sustentam em informações que extraem da oralidade, ora em informações que extraem da escrita, de modo que nem sempre há prevalência de um em relação ao outro. Os autores ainda verificaram que as sílabas acentuadas concentram maior intensidade e duração que as não-acentuadas e que isso não fará com que elas sejam menos omitidas. Isso acontece porque os professores, na prática pedagógica (geralmente com ditados), tendem a separar as palavras em sílabas para as crianças: isso enfatiza a quantidade de sílabas no interior de uma palavra geralmente minimizando o contraste entre as sílabas acentuadas e não acentuadas. Isso evidencia o caráter heterogêneo da escrita, porque mostra que as crianças não partem apenas das características da fala quando escrevem, mas também os conhecimentos que ganham nas práticas pedagógicas (AMARAL et al., 2011, p. 853).

A hipótese diagnóstica de Dislexia foi levantada e as indicações foram a de atendimento psicopedagógico, avaliação neuropediátrica e, se necessário, acompanhamento psicológico em caso de persistência das dificuldades. A psicopedagoga (que também é a autora do artigo aqui analisado, já que Altreider tem formação em psicopedagogia e fonoaudiologia) que acompanhou Ana Maria elaborou dois quadros comparativos sobre a evolução da leitura e da escrita, que reproduzimos adiante. Ela faz um comparativo entre os meses de abril e outubro. Com relação à escrita, Ana Maria deixou de escrever palavras isoladas que havia decorado e passou a escrever pequenos textos lógicos, demonstrando alegria ao fazê-lo. Passou a escrever bilhetes e cartas expressando afeto para a psicopedagoga. Com relação à leitura, Ana Maria deixou de soletrar e passou a silabar, lendo poucas palavras com fluência, mas, em relação ao mês de abril, apresentou crescimento na decodificação, segundo a autora, já que a compreensão do texto depende mais das ilustrações do que da leitura. 
Figura 2. Análise comparativa da leitura e da escrita de Ana Maria

\section{ESCRITA}

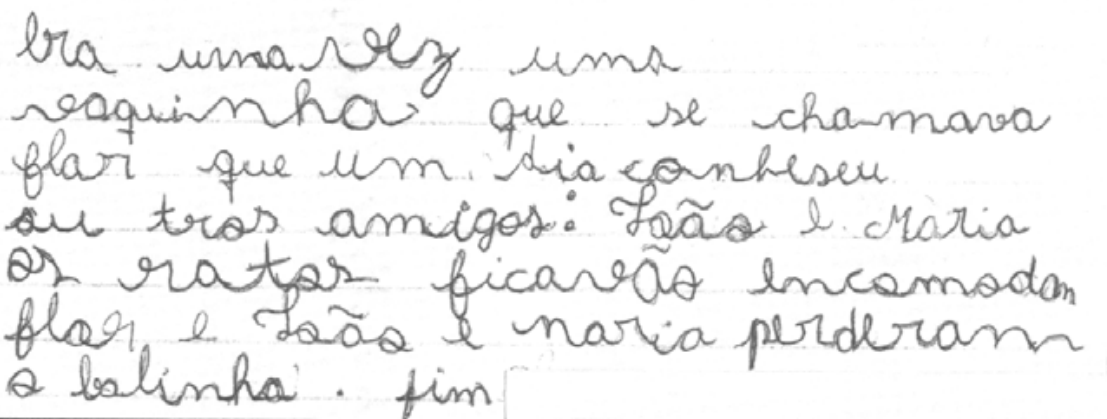

Figura 14.5 Escrita atual de Ana Maria.

Fonte: Altreider (2015, p. 239)

Figura 3. Análise comparativa da leitura e da escrita de Ana Maria

\section{LEITURA}

TEXTO ORIGINAL

$$
\begin{aligned}
& \text { PATINANDO NO GELO } \\
& \text { Deixando para trás o barulhinho dos } \\
& \text { chocalhos das cabras, Kika } \\
& \text { continuou subindo até chegar a uma } \\
& \text { pista de patinação. O } \\
& \text { caminho era mais ingreme, o ar mais } \\
& \text { frio. A competição estava para começar } \\
& \text { no rinque já lotado. Mas quatro concor- } \\
& \text { rentes pareciam tristonhos. } \\
& \text { - Ajude aqui, Kika! - pediram eles. - } \\
& \text { Não conseguimos encontrar nosso par, } \\
& \text { com toda essa gente no rinque. Eles } \\
& \text { usam roupas iguais as nossas. }
\end{aligned}
$$

LEITURA DE ANA MARIA

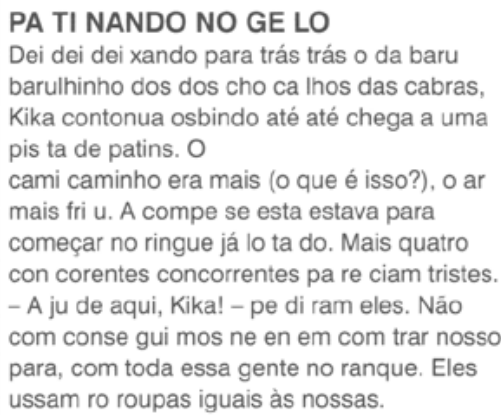

Observação: este texto foi retirado do livro A montanha nevada, de Leigh (20--), da coleção Pedra no caminho, da qual Ana Maria lê em cada consulta um capítulo.

Fonte: Altreider (2015, p. 238)

Como vemos, a psicopedagoga reconhece a melhora de Ana Maria e, diferente da tendência que observamos em relatórios, ressalta também o que ela já aprendeu em vez de ter como foco apenas o que ela não faz ainda, o déficit. O relatório nos faria supor que, diante da melhora em tão pouco tempo, do fato de Ana Maria estar menos resistente à escola, de ter significativas melhoras na leitura, a psicopedagoga consideraria que ela era uma criança que tinha dificuldades e que está conseguindo superá-las. Entretanto, 
ela continua afirmando que há significativas evidências de que Ana Maria tem Dislexia, desconsiderando a melhora apresentada e tomando como base apenas as dificuldades iniciais que a criança demonstrava:

Ana Maria é uma menina de 9 anos e 4 meses que apresenta significativas dificuldades que envolvem o processo de aprendizagem, particularmente na leitura. Há significativas evidências que fazem supor que se trata de um caso de dislexia. Está em atendimento psicopedagógico semanal há seis meses e apresenta melhora significativa. As evidências apontavam para uma ruptura na relação aluno-escola. Essa relação ainda não está restaurada, mas apresenta melhoras na medida em que a menina está apresentando menor sofrimento e cumpre com maior desenvoltura as suas tarefas. A preocupação familiar com a aprendizagem de Ana Maria é total. A articulação na busca de diagnóstico e terapia de forma estruturada, objetiva e científica, é parcial. A ausência de diagnóstico formal impede ações mais efetivas em relação à escola. [...]. Perceber que com todo conhecimento disponível nas mais diferentes mídias e, mesmo assim, não evoluirmos de forma consistente no enfrentamento de oferecer recursos aos portadores de dislexia é desalentador. A maioria dos casos continua não identificada. Os identificados dependem de um conjunto de boas vontades e não de um padrão de atendimento, mesmo que isso seja um direito adquirido. (ALTREIDER, 2015, p. 243-244).

A autora milita pela consolidação do diagnóstico o mais breve possível, para que Ana Maria receba atendimento específico na escola - o que a tornará uma criança café com leite (COUDRY, 2010) naquele ambiente onde um laudo justifica atividades que exigem menos dela e dela tudo toleram. A análise deste caso e da teoria que embasa o capítulo escrito por Altreider em contraposição à análise deste artigo nos mostra a interincompreensão (MAINGUENEAU, 2005) entre o entendimento clínico e o entendimento da ND sobre o que se considera dislexia. Partindo de nossas concepções de sujeito, cérebro, língua e linguagem - radicalmente opostos às concepções clínicas tradicionais -, nossa análise aponta que Ana Maria não está aprendendo apesar do suposto transtorno e das dificuldades que apresenta, mas sim porque o acompanhamento ao qual é submetida está ajudando-a a superar suas dificuldades. Ela não tem dificuldades porque nasceu com questões biológicas, mas porque seu contexto histórico, social e pedagógico é gerador de suas questões escolares. Para a ND, os dados de escrita de Ana Maria não evidenciam sintomas, mas sim processo de aprendizagem em curso. O fato de que este é o livro mais vendido sobre neurociência relacionada à aprendizagem nos fornece indícios de que o tipo de discurso com o qual os professores têm contato nesta nova tendência de formação continuada é patologizante e contribui para a formação ou manutenção do olhar clínico (HORA, 2001) do professor. Alertamos, aqui, para o fato de que essa tendência está cada vez mais forte não apenas no mercado editorial, mas começa a ser 
defendida também pelas diretrizes nacionais e internacionais ${ }^{10}$, embasando as políticas públicas de formação de professores e as decisões do governo sobre o fracasso escolar.

\section{Discussão}

O alerta que a ND faz a respeito desta nova tendência se alinha à crítica feita por Stanislas Morel sobre o domínio das neurociências no debate sobre educação. Em entrevista ao jornal Libération (MOREL; CARIO, 2018), o sociólogo francês, especialista em medicalização do fracasso escolar na França, ressalta que o fenômeno das neurociências não é tão recente assim no debate educacional, já que sempre esteve presente com outras nomenclaturas. Entretanto, a partir de 2010, a terminologia neurociência ganhou força por conta do avanço das técnicas de exploração do cérebro e de exames que supostamente avaliam áreas envolvidas na aprendizagem. Na perspectiva do autor, algumas linhas de pesquisa das neurociências aplicadas à Educação receberam diversas críticas que as acusaram de privilegiar o determinismo biológico. Diante disso, buscaram explorar melhor o papel da plasticidade cerebral na aprendizagem e a capacidade do cérebro de se modificar pelas interações sociais. Nesse movimento, a área passou a adotar um discurso integrativo que leva em conta o que chamam de fatores biopsicossociais e que determinam a aprendizagem. Entretanto, as neurociências, ao invés de coordenar as diferentes abordagens que articulou para tratar da aprendizagem, estabeleceu entre elas uma hierarquia na qual as ciências biológicas estão em primeiro lugar. As neurociências aplicadas à educação relativizam os questionamentos ontológicos sobre o fracasso escolar para privilegiar um pragmatismo biológico que traz respostas mais práticas e simples para explicar as dificuldades e soluções, como a repetição dos exercícios, a correção sistemática dos erros, as maneiras de se memorizar mais rápido a partir de estudos sobre o cérebro e até mesmo como melhorar a autoestima dos alunos com estratégias de repetição de autoafirmações e de frases de otimismo. Assim, o que explica a atratividade à neurociência é que muitos hoje acreditam que ela é uma disciplina de vanguarda, capaz de fornecer soluções para problemas escolares e sociais.

10 Dois exemplos dessa tendência são os casos da França e do Brasil. Na França, no início de 2018, o ministro da educação nomeou Stanislas Dahene para a presidência do Conselho Científico da Educação Nacional. Dahene é psicólogo da abordagem cognitiva e principal representante da abordagem que relaciona neurociência à educação na França. Já no Brasil, o decreto de 11 de abril de 2019 do presidente Jair Bolsonaro que versa sobre a nova política nacional de alfabetização determina que, a partir de sua posse, o Ministério da Educação deverá tomar a "fundamentação de programas e ações em evidências provenientes das ciências cognitivas" e determina, com base em estudos internacionais provenientes das neurociências/ciências cognitivas, que o método de alfabetização a ser adotado no Brasil deve ser o fônico. Ademais, o presidente escolheu Carlos Nadalim para o cargo de secretário de alfabetização, um dos principais defensores do uso do método fônico no Brasil. 
Para Morel, construir uma crítica à abordagem da neuroeducação não é simples. O discurso dos neurocientistas envolve e enfatiza o rigor e a avaliação "objetiva" dos resultados dos experimentos e das atividades escolares e se alinha aos direcionamentos das políticas públicas. As conclusões da neurociência tomam como base resultados de avaliações nacionais e seus indicadores de desempenho - e apontam soluções para a melhoria dos índices -, o que agrada aos órgãos públicos. Além disso, os neurocientistas geralmente têm atitudes muito ofensivas em relação a disciplinas concorrentes (como as Ciências Sociais, que, como aponta Morel, para muitos pesquisadores, não teriam legitimidade para abordar as dificuldades escolares) ou certas profissões (como professores, criticadas do ponto de vista de suas práticas, que também não são validadas justamente por não partirem ainda da abordagem neurocientífica). Entretanto, Morel alerta que em outros contextos os neurocientistas adotam posturas ecumênicas e cautelosas, com as quais exibem uma abertura multidisciplinar e apelam para as competências de cada um. Por causa dessa ambivalência no discurso, a crítica da neurociência é difícil, assim como a construção de uma troca científica de longo prazo, que exigiria uma boa compreensão das posições de cada um.

Assim, as neurociências são um mecanismo de confirmação de soluções ou métodos pré-existentes: não há, de fato, muitas novidades. Como exemplo, ele cita o fato de que o novo secretário francês apontou que o método fônico deve ser o privilegiado em sala de aula pela eficácia comprovada e pela rapidez que ele promete na aprendizagem. Segundo Morel, isso não é novidade para os professores, que conhecem esse método e já o aplicam em vários contextos. O que é novo é a maneira de administrar a prova da eficácia das práticas pedagógicas. E é a partir do efeito de alavanca criado por essa forte legitimidade científica que os neurocientistas puderam validar de recomendações que eles mesmos admitem não serem particularmente revolucionárias. Para a ND, há controvérsias a serem consideradas em relação ao método fônico, sobretudo a transparência entre som e sua representação escrita. Morel ressalta também o papel da família das crianças com dificuldades escolares. A neurociência forneceu-Ihes diagnósticos percebidos como mais interessantes do que os que prevaleciam até então (deficiência intelectual, disfunção familiar, etc.).

Se considerarmos o que hoje chamamos de "nebulosa" de distúrbios específicos de aprendizagem, a palavra mais importante é "especifica": apenas um processo cognitivo é afetado, e para o resto, a criança é normal, mais inteligente do que as outras. Além da questão de sua validade científica, são, portanto, diagnósticos quase recompensadores, que fazem com que os pais se sintam menos culpados. São ainda muito lucrativos no mercado escolar: a necessidade de lidar com crianças portadoras dessas patologias, como observa Morel, gera a contratação de professores especializados em dificuldades e também ajustes pedagógicos que envolvem cursos para os professores em geral. Isso explica, em parte, que houve uma explosão desses distúrbios e o fato de que as instituições clínicas que lidam com isso estão com alta demanda. 0 autor conclui que as neurociências, na contemporaneidade, se colocam como ciências de vanguarda, o 
que mobiliza o mercado e os pesquisadores na promoção da disciplina, bem como os consumidores que se interessam sempre em saber o que há de novo em termos de educação. Dessa forma, compreende-se o aumento da oferta de livros e cursos deste tema apontados no início deste artigo. Entretanto, com Morel, a ND alerta para o fato de que a onda das neurociências - a chamada neuroeducação e a obsessão que essas disciplinas têm pelo desempenho escolar, pelos resultados de avaliações padronizadas de larga escala - não são apenas um dispositivo de patologização (COUDRY 2007, 2009; AGAMBEN 2009), mas também um dispositivo de despolitização do debate sobre a educação.

\section{Conclusão}

Deslocando o foco do debate para o cérebro, o sujeito biológico, os resultados das provas, o que envolve a codificação e a decodificação (já que, para essas ciências, essas palavras são sinônimos de aprendizagem) e os supostos transtornos, as neurociências apagam as desigualdades sociais, a precarização das escolas, a formação pedagógica do professor (para defender sua formação na neurociência do aprender) e o sujeito histórico, social, cultural e psíquico que mantém uma relação singular com a linguagem - como Ana Maria, cuja história é ressignificada neste artigo pela análise da ND. Silenciar esse debate com a imposição de uma teorização e prática meramente organicistas, como a Neuroeducação, exime governo, escolas, professores e família da responsabilidade pelo aprendizado da criança. Na contemporaneidade, a neurociência, com sua suposta efetividade comprovada em pesquisas internacionais e a multidisciplinaridade que aparentemente a constitui, parece blindar-se das críticas provenientes das ciências humanas, das ciências da linguagem e da pedagogia. A ND aponta, assim, para a necessidade de que as ciências humanas e sobretudo a Linguística reivindiquem seu protagonismo na pesquisa e na análise das dificuldades de leitura e escrita e problematize constantemente o excesso de diagnósticos advindo do fato de que a medicina cada vez mais ocupa um lugar que não Ihe pertence na educação, patologizando, com o chamado discurso neurocientífico, as dificuldades escolares comuns no processo de aprendizagem de leitura e escrita.

\section{REFERÊNCIAS}

ABAURRE, M. B.; FIAD, R. S.; MAYRINK-SABINSON, M. L. Cenas de aquisição da escrita. Campinas: Mercado de Letras, 2006.

BORDIN, S. Fala, leitura e escrita: encontro entre sujeitos. 2010. Tese (Doutorado em Linguística) - Instituto de Estudos da Linguagem, Universidade Estadual de Campinas, Campinas, 2010.

AGAMBEN, G. O que é contemporâneo? e outros ensaios. Chapecó: Argos, 2009. 
ALTREIDER, A. Dislexia: varlendo contra o vento. In: ROTTA, N. T.; BRIDI FILHO, C. A.; BRIDI, F. de S. (org.). Neurologia e Aprendizagem: abordagem multidisciplinar. Porto Alegre: Artmed, 2015.

AMARAL, A.; FREITAS, M. C. C. de; CHACON, L.; RODRIGUES, L. L. Omissão de grafemas e características da sílaba na escrita infantil. Rev. CEFAC, v. 13, n. 5, p. 846-855, set./out. 2011.

AMERICAN PSYCHIATRIC ASSOCIATION (APA). Manual diagnóstico e estatístico de transtornos mentais: DSM-5. Porto Alegre: Artmed, 2014.

CAGLIARI, L. C. Alfabetização e linguística. São Paulo: Scipione, 1989.

CONRAD, P. Medicalization and social control. Annu. Rev. Sociol., n. 18, 1992.

COUDRY, M. Diálogo com a Neurolinguística para a formação de professores. In: SERRANI, S. Letramento, discurso e trabalho docente. Vinhedo: Horizonte, 2010.

COUDRY, M. Despatologizar é preciso. In: II SIMELP: Panorâmica de Linguística, Literatura e Cultura. Anais do evento. Évora: Universidade de Évora, v. 1, 2009.

COUDRY, M. Patologia estabelecida e vivências com o escrito. ENAL. Anais do $7^{\circ}$ Encontro Nacional sobre Aquisição da Linguagem. Porto Alegre: PUCRS, 2007.

COUDRY, M.; FREIRE, F. Fala e Leitura uma (re)entrada para a escrita. Cadernos de Estudos Linguísticos. Homenagem a Maria Bernadete Marques Abaurre, Campinas, v. 59.3, p. 565-579, set./dez. 2017.

FRANCHI, C. Linguagem: atividade constitutiva. Cadernos de Estudos Linguísticos, n. 22, 1992.

FREUD, S. La afasia. Buenos Aires: Ediciones Nueva Visión, 1973.

HELLER-ROAZEN, D. Ecolalias. Campinas: Editora UNICAMP, 2010.

HORA, D. M. O olho clínico do professor. Rio de Janeiro: Contra-Capa, 2011.

LURIA, A. R. El cérebro en acción. Barcelona: Fontanela, 1979. 
LURIA, A. O desenvolvimento da escrita na criança. In: VYGOTSKY, S.; LEONTIEV, A. Linguagem, desenvolvimento e aprendizagem. São Paulo: Ícone, 2001.

LURIA. A. Curso de psicologia geral. v. 3. Rio de Janeiro: Civilização Brasileira, 1991.

MAINGUENAU, D. Gênese dos discursos. Curitiba: Criar Edições, 2005.

MOREL, S.; CARIO, E.; "Interview. Stanislas Morel: «Les neurosciences illustrent la dépolitisation actuelle de la question scolaire»». Libération (online), 19 de janeiro de 2018. Disponível em: https://www.liberation.fr/debats/2018/01/19/stanislas-morelles-neurosciences-illustrent-la-depolitisation-actuelle-de-la-question-scolaire_1623801. Acesso em: 14 jun. 2019.

MOUTINHO, I. Contribuições da Neurolinguística Discursiva para a formação de professores. 2019. Tese (Doutorado em Linguística) - Instituto de Estudos da Linguagem, Universidade Estadual de Campinas, Campinas, 2019.

MOYSÉS, M. A. A Institucionalização Invisivel: crianças que não aprendem na escola. Campinas: Mercado de letras; São Paulo 2001.

MOYSÉS, M. A. A.; COLLARES, C. A. L. Dislexia e TDAH: uma análise a partir da ciência médica. In: Conselho regional de Psicologia de São Paulo (org.). Medicalização de Crianças e Adolescentes: conflitos silenciados pela redução de questões sociais a doenças de indivíduos. São Paulo: Casa do Psicólogo, 2010. p. 71-110.

MÜLLER, L. Patologização e fracasso escolar: desnaturalizando respostas. 2018. Tese (Doutorado em Linguística) - Instituto de Estudos da Linguagem, Universidade Estadual de Campinas, Campinas, 2018.

RIGHI-GOMES, M. Reflexões sobre práticas docentes à luz da Neurolinguística Discursiva. 2014. Tese (Doutorado em Linguística) - Instituto de Estudos da Linguagem, Universidade Estadual de Campinas, Campinas, 2014.

SIGNOR, R.; SANTANA, A. TDAH e medicalização: implicações neurolinguísticas e educacionais do déficit de atenção /Hiperatividade. São Paulo: Plexus, 2016.

VYGOTSKY, L. S. Psicologia pedagógica. São Paulo: Martins Fontes, 2001. 